\title{
EDITORIAL
}

\section{Rural and remote medicine}

In the last proper Canadian census conducted in 2006, it was determined that $20 \%$ of Canada's population resided in rural locations. This percentage translates into 6.2 million people residing outside of urban centres! Given Canada's enormous geographical size, this creates huge challenges in the provision of medical care for the $20 \%$ of the population scattered in rural and remote regions. As those of us training at the Schulich School of Medicine and Dentistry are aware, many of our fellow classmates are from rural areas throughout Southwestern Ontario. For those of us raised in urban centres, we have had a myriad of opportunities during our preclerkship and clerkship training to explore these rural locations outside of London and experience the life of a rural physician for ourselves. Some of the fondest memories of my clerkship experience occurred outside of urban centres and in smaller communities. As for my own class, many students seized the opportunity to not only explore smaller communities in southwestern Ontario during our clerkship training, but went even further afield to remote locations in northern Ontario, northern British Columbia and rural Alberta. If the beautiful photographs of these adventures posted on social media are any indication, these classmates were all rewarded for their adventurous spirit with fantastic experiences and memories that will last a lifetime. It was no surprise during this year's CaRMS match that many of my classmates matched to family medicine residency training programmes in rural locations. In fact, many of these positions are becoming highly sought-after training opportunities.

This issue of the UWOMJ is dedicated to the theme of rural and remote medicine. Many of us will become rural physicians and will be faced with many challenges providing healthcare for our patients in resource-limited areas. Others of us will practice in urban centres. However, we should not forget the plight of our colleagues in rural areas as sound public policy surrounding the delivery of healthcare to rural areas should be important to us all. I hope that you enjoy reading the articles detailing the various challenges and strategies at play in the delivery of rural and remote medicine from a medical student perspective.

As for myself, I have spent a wonderful four years at the Schulich School of Medicine and Dentistry. It has been an honour and a privilege to serve as this year's editor-inchief of the UWOMJ, now in its 84th year of publication. I hope that the journal continues to serve as a forum in which medical students can publish scholarly work for many years to come. This publication would not be possible without a large team of dedicated students making it happen. I wish to thank the wonderful colleagues with whom I have had the pleasure of working this past academic year. I now hand over the reins to our next editor-in-chief Jason Chan.

Melissa J MacPherson, PhD (Meds 2014) Editor in Chief 